\title{
PREVENTING DOMESTIC VIOLENCE IN ALBERTA: A COST SAVINGS PERSPECTIVE
}

\author{
Lana Wells, Brenda Strafford Chair, Prevention of Domestic Violence, \\ Faculty of Social Work, University of Calgary \\ Casey Boodt, Researcher, and \\ Herb Emery, Department of Economics, University of Calgary
}

\section{SUMMARY}

Recent studies show that Alberta has the fifth highest rate of police reported intimate partner violence and the second highest rate of self reported spousal violence in Canada, and despite a 2.3 percent decline over the last decade, the province's rate of self-reported domestic violence has stubbornly remained among the highest in Canada; rates of violence against women alone are 2.3 percentage points higher than the national average. In fact, every hour of every day, a woman in Alberta will undergo some form of interpersonal violence from an ex-partner or ex-spouse. Besides the devastating toll that domestic violence has on victims and their families, the ongoing cost to Albertans is significant. In the past five years alone it is estimated that over $\$ 600$ million will have been spent on the provision of a few basic health and non health supports and that the majority of this cost ( $\$ 521$ million) is coming out of the pockets of Albertans in the form of tax dollars directed at the provision of services. Fortunately, investment in quality prevention and intervention initiatives can be very cost effective, returning as much as $\$ 20$ for every dollar invested. Recent research on preventative programming in the context of domestic violence shows promising results in reducing incidents of self-reported domestic violence. The economic analysis of this preventative programming suggests that the benefits of providing the various types of programming outweighed the costs by as much as 6:1. The potential cost savings for the Alberta context are significant; the implementation of these preventative programs has been estimated to be approximately $\$ 9.6$ million while generating net cost-benefits of over $\$ 54$ million. Domestic violence is a persistent blight, and continues to have a significant impact on individuals and families in Alberta, but potent tools exist to fight it. This brief paper offers a cogent summary of its costs, and the benefits that could be reaped by investing in quality prevention and intervention programs, making it essential reading for policymakers and anyone else prepared to use them. 
Research for this study was supported by the Canadian Women's Foundation.

\section{About the Authors}

Lana Wells, Brenda Strafford Chair in the Prevention of Domestic Violence, Faculty of Social Work, University of Calgary

In August 2010, Lana Wells was appointed to the role of The Brenda Strafford Chair in the Prevention of Domestic Violence. In that same year, Lana created Shift: The Project to End Domestic Violence. Shift is a ground-breaking, community-based project focused on significantly reducing, and eventually ending domestic violence in Alberta. The name Shift represents the spirit of this initiative aimed at creating transformational change, using a primary prevention approach to stop first-time victimization and perpetration of domestic violence. Over the past two years, Lana has been focused on a comprehensive research agenda and consultations with academics, community and policy experts to develop appropriate and sustainable strategies that will influence programs and policies and over time, change social and cultural norms. Most recently, Lana and Shift are working with the Government of Alberta's Ministry of Human Services to redesign the Family Violence Prevention Strategy. This is a significant opportunity to build primary prevention into government policy, strategy and resource allocations.

Casey Boodt, M.Ed. President, CPB Consulting Inc.

Casey Boodt has been working in the social services sector for the past 12 years in the area of vulnerable children, youth, and families, initially doing direct intervention work, and then becoming involved in program development and evaluation. Casey has a Masters Degree in Educational Psychology and extensive experience in strategy development, program design and evaluation. Casey has authored an annual report for the United Way of Calgary (Measuring Up) that examines the economic impact of investing in programs directed at homelessness, the prevention of homelessness, and unemployment, and, is currently working with UpStart: Champions for Children and Youth, a United Way of Calgary Initiative, in the design and implementation of their "Cradle to Career" Collective Impact Framework.

Herb Emery, received his BA (Honours) in economics from Queen's University in 1988 and PhD in economics from the University of British Columbia in 1993. He has taught at the University of Calgary since 1993 and is now the Svare Professor in Health Economics which is a joint appointment between the Department of Economics and the Department of Community Health Sciences in the Faculty of Medicine. Dr. Emery's current research includes "The Rise of Public Health Insurance Before 1930," "The Sustainability and Reform of Public Health Care in Canada", and "Western Canadian Economic Development". 


\section{INTRODUCTION}

Research in public policy advocacy shows that once policymakers have an understanding of both the economic and social burdens of a problem, and the cost savings that can be generated by strategies designed to address the problem, they then have an easier time endorsing and promoting policy addressing the social problem in question. ${ }^{l}$

Following this line of thinking, the authors felt that in order to successfully advance a primary prevention strategy to reduce domestic violence in Alberta, it would be beneficial to help policymakers understand the heavy economic costs associated with domestic violence, as well as identify strategies, policies, and evidence-based programs that could significantly reduce the rates of domestic violence.

This paper illustrates the economic burden associated with domestic violence in Alberta, and how the prevention of domestic violence can be cost-effective when strategies that have proven to be efficacious are implemented, monitored and evaluated. And while the focus of the paper is on Alberta, the findings and recommendations are applicable to other jurisdictions across Canada.

This paper is part of a larger research project that seeks to support the development of a primary prevention framework for domestic violence in Alberta. As such, this report is only a first step in moving that agenda forward. The information presented illustrates the economic burden associated with domestic violence after the victimized partner leaves such a relationship. Therefore, the costs associated with domestic violence suffered while the victimized partner and any affected children remain in the relationship are not identified here.

The costs identified in this report, then, represent only a small portion of the total costs associated with addressing, and dealing with domestic violence. Even so, we will argue that these costs are sufficiently large and unequivocal, and that the implementation of effective prevention and intervention strategies are likely to yield significant cost savings, not only to the individuals involved, but also to governments whose programs in health, policing and social assistance bear the major cost burden associated with domestic violence.

The information presented in this paper relies on recent literature that explores the economic and social burden associated with domestic violence, and research that explores prevention and intervention strategies that have been found to be effective. In other words, strategies that make a measurable difference for those who undergo the intervention, but are also cost-effective, meaning that cost savings can be realized at both an individual and societal level.

1 Prevention Action (2011). "Speaking the language of policy," Prevention Action, October 2011. Retrieved October 31, 2011 from http://www.preventionaction.org. 
Although the literature reviewed uses the terms domestic violence, ${ }^{2}$ family violence, ${ }^{3}$ violence against women, ${ }^{4}$ and intimate partner violence, ${ }^{5}$ for the purposes of this report, the terms domestic violence and interpersonal violence will be used interchangeably and follow the definition laid out by the Centres for Disease Control and Prevention.

\section{FINDINGS AND IMPLICATIONS}

\section{Domestic Violence is Pervasive and Costly}

In a 2009 report exploring domestic violence, the Department of Justice for Canada stated "the results of national research and surveys have made it clear that [domestic] violence is not just an individual, private or family matter; it is a pervasive and complex societal problem in Canada." The report defines domestic violence as including many different forms of abuse, mistreatment or neglect that adults or children may experience in their intimate, family or dependent relationships. It notes that in the last 20 years, more attention is being paid to violence against women in intimate relationships, spousal abuse, dating violence and other forms of violence against women. ${ }^{7}$

The realization that domestic violence, and specifically violence against women, is a pervasive and complex societal problem is echoed in the literature and research that examines the cost of domestic violence. The authors of one study concluded that with evidence from costing studies, "it is no longer possible to conclude that violence against women is a 'private' problem; rather it is unquestionably a 'public' problem because the whole of society pays monetarily."

2 The Calgary Domestic Violence Committee (CDVC) defines domestic violence as "the attempt, act or intent of someone within a relationship, where the relationship is characterized by intimacy, dependency or trust, to intimidate either by threat or by the use of physical force on another person or property. The purpose of the abuse is to control and or exploit through neglect, intimidation, inducement of fear or by inflicting pain. Abusive behaviour can take many forms including: verbal, physical, sexual, psychological, emotional, spiritual and economic, and the violation of rights. All forms of abusive behaviour are ways in which one human being is trying to have control and/or exploit or have power over another."

3 According to the government of Alberta, family violence is the abuse of power within relationships of family, trust or dependency that endangers the survival, security or wellbeing of another person. It can take many forms including spouse abuse, senior abuse and neglect, child abuse and neglect, child sexual abuse, parent abuse, and witnessing abuse of others in the family. Family violence may include some or all of the following behaviours: physical abuse, psychological abuse, criminal harassment/stalking, verbal abuse, sexual abuse, financial abuse and spiritual abuse.

4 The United Nations (1993) defines violence against women as any act of gender-based violence that results in, or is likely to result in, physical, sexual or psychological harm or suffering to women, including threats of such acts, coercion or arbitrary deprivation of liberty, whether occurring in public or private life. It is understood to occur on a continuum of economic, psychological and emotional abuse through to physical and sexual violence.

5 The Centers for Disease Control (2003) define intimate partner violence as any physical, sexual or emotional abuse by a current or former partner or spouse.

6 Department of Justice Canada. (2009). Family Violence: Department of Justice Canada Overview Paper 2009. P. 8-9. Department of Justice Canada, Ottawa, Ontario, Canada. Online report available at http://www.justice.gc.ca/eng/pi/fv-vf/facts-info/fv-vf/fv-vf.pdf.

7 Department of Justice Canada (2009). Op. cit.

8 Godenzi, A. \& Yodanis, C. (2000). "The benefits of studying costs: A review and agenda for studies on the economic costs of violence against women,” P.273. Policy Studies, 21(3): 263-276. 
Research over the past 30 years has examined the wide range of economic costs associated with domestic violence in numerous jurisdictions. For the victims and their families, the violence impacts their psychological and emotional wellbeing, destabilizes the family, causes lost time at work in the short run, and disrupts and thwarts career opportunities over the longer term. ${ }^{9}$ Domestic violence also results in the significant use of policing resources, social service interventions and medical treatment, and contributes significantly to the burden of disease and mortality. ${ }^{10}$

Quantifying the social costs associated with domestic violence is not a straightforward exercise given the extensive list of the direct and indirect costs of domestic violence that should be considered, and the challenges of estimating the incidence and prevalence of domestic violence. $^{.1}$

Consequently, most social cost estimates of domestic violence are considered conservative estimates of the true full cost.

In Canada, the first study to examine economic costs of violence specifically against women was conducted by Day, focused on health ${ }^{12}$ and estimated the total measurable costs to be $\$ 1.5$ billion for 1993 (\$2.1 billion in 2011 purchasing power). In another study, Greaves, Hankivsky and Kingston-Riechers, ${ }^{13}$ considered multiple forms of violence and a wide range of costs including employment, legal, health and social service sectors, and estimated the selected costs to be $\$ 4.2$ billion annually ( $\$ 5.75$ billion in 2011 purchasing power). ${ }^{14}$

9 In the United States, the Centers for Disease Control (2003) reported that the health related costs of rape, physical assault, stalking, and homicide against women by their intimate partners exceeded $\$ 5.8$ billion annually. In Finland, Heiskanen and Piispa (2001) estimated the annual costs of violence against women at US\$136-198 million in 1998. In the United Kingdom, Walby ((2009) The Cost of Domestic Violence: Update 2009. Lancaster University, Lancaster, U.K.) estimated the total costs of domestic violence for the public sector, employers and victims at $£ 15.7$ billion annually. In Australia, the total costs of domestic violence in 2002-03 were estimated to be $\$ 8.1$ billion and constituted one percent of the total burden of disease (Access economics 2004; Begg et al., 2007). This estimate included the cost of pain, suffering and premature mortality, health-related costs, production-related costs (e.g., work time lost), consumption-related costs (e.g., services used), second-generation costs, and administrative costs for all affected groups: victims, perpetrators, children, family and friends, employers, all levels of government, and the rest of the community/society. More recently, the National Council to Reduce Violence against Women and Their Children (2009) estimated that the costs of violence against women in Australia have increased to \$13.9 billion.

10 Begg, S., Vos, T., Barker, B., Stevenson, C., Stanley, L., \& Lopez, A. D. (2007). The Burden of Disease and Injury in Australia 2003. PHE 82. Australian Institute of Health and Welfare, Canberra.

11 See Corso, P. (2009). "Economic analysis and the prevention of intimate partner violence," in C. Mitchell \& D. Anglin (Eds.), Intimate partner violence: A health-based perspective, (pp. 53-60). Oxford University Press: New York; Day, T., Mckenna, K., \& Bowlus, A. (2005). The Economic Costs of Violence Against Women: An Evaluation of the Literature. Expert brief compiled in preparation for the Secretary-General's in-depth study on all forms of violence against women. University of Western Ontario, London, Ontario, Canada; Varcoe, O., Hankivsky, M., FordGilboe, J., Wuest, P., Wilk, J., Hammerton, J., and Campbell, J. (2011). "Attributing selected costs to intimate partner violence in a sample of women who have left abusive partners: A social determinants of health approach," Canadian Public Policy - Analyse de politiques, 37(3): 1-21.

12 Day, Tanis. (1995) “The Health Related Costs of Violence Against Women: The Tip of the Iceberg," first commissioned by the Canadian Advisory Council on the Status of Women, published by The Centre for Research on Violence Against Women and Children, University of Western Ontario, London, Ontario, Canada.

13 Greaves, L., Hankivsky, O., \& Kingston-Riechers, J. (1995). Selected Estimates of Costs of Violence against Women. Centre for Research on Violence against Women and Children, London, Ontario, Canada.

14 The cost conversion of the original estimates provided by Day (1995) and Greaves et al. (1995) were calculated using the Consumer Price Index. 
More recently, a 2011 study conducted by Varcoe et al., examined the magnitude of a select number of costs associated with domestic violence after women have left abusive partners, and estimated that the annual national cost of dealing with the ongoing effects of such violence to be $\$ 6.9$ billion. $^{15}$

\section{The Prevalence of Domestic Violence in Alberta}

Studies that examine the economic costs associated with any type of preventable and pervasive social problem such as domestic violence rely on a variety of counts or estimates of the incidence, prevalence, morbidity and mortality of the issue in question. ${ }^{16}$ This data is usually gathered through surveys, health registries and police records. In Canada, information on the incidence and prevalence of domestic violence is gathered annually through the Uniform Crime Reporting Survey and the General Social Survey which include items on self-reported spousal victimization on a five-year cycle. Based on these data, estimates are then calculated for the percentage of those who self-reported spousal victimization in the past five years. ${ }^{17}$

\section{Attempting to Estimate the Prevalence of Domestic Violence in Alberta}

As noted in the text there are really only two sources of data for calculating an estimate of the prevalence of domestic violence for a province; the Incident-based Uniform Crime Reporting Survey, or the General Social Survey (GSS). The data is gathered by Statistics Canada, with reports being produced by the Canadian Centre for Justice Statistics, and the estimates will vary depending on the source used.

For example, the 2011 Family Violence in Canada: A Statistical Profile report is based on a percentage of Canadians in 2009 that had a current or former spouse. In 2009 of the 19 million Canadians that had a current or former spouse, six percent or 1,140,000 reported that they had been either physically or sexually assaulted by their partner or spouse in the last five years.

The percentage of those reporting the same thing in Alberta for 2009 was 7.6 percent. In 2009 there was a total of 976,620 census families in Alberta. A census family is either a husband-wife, common-law or single parent with any marital status and so appears to fit the criteria of having a current or former spouse. Based on this census number and a prevalence rate of 7.6 percent this equates to just over 74,223 men and women who reported having been either physically or sexually abused by a spouse or partner in the past five years. This works out to an average of $\mathbf{1 4 , 8 4 5}$ per year.

The 2009 Family Violence in Canada Report, which relies on data from the 2007 Uniform Crime Reporting Survey, provides an incidence rate of $249 / 100,000$ which, based on Alberta's population in 2007 , works out to $\mathbf{8 , 4 6 6}$ men and women who are dealing with domestic violence on an annual basis.
This same report also indicates that eight out of every 10 victims of domestic violence is a woman. If eight out of every 10 victims of domestic violence are women, then depending on whether we use the prevalence number or the incidence number, we get two possible estimates of the number of women who report abuse from an ex-spouse or partner on an annual basis: $\mathbf{1 1 , 8 7 5}$, based on the 7.6 percent prevalence rate for Alberta, and $\mathbf{6 , 7 7 3}$ based on an incidence rate of $249 / 100,000$.

If, on the other hand, we use the incidence rate of domestic violence obtained from the 2009 Statistics Canada Family Violence Report (8.7 percent for women Alberta) and apply it to the women who reported in the 2006 Census for Alberta $(103,355)$ that they were legally separated or divorced and not living with a partner (same criteria used in the Varcoe et al., study for their national sample), we get an estimate of 8,992 women in Alberta who can be deemed to be either dealing with, or have left and are dealing with the effects of domestic violence on an annual basis.

Finally, detailed analysis of the 2009 GSS survey data for Alberta reveals that there were 45,837 women who indicated that they had an 'ex', and that they had experienced one or more incidents of physical or sexual violence in the past five years which works out to an average of $\mathbf{9 , 1 6 7}$ on an annual basis.

The net result of this analysis yields a range of estimates from 6,773 to 11,875 with the mid-point of the two extremes being 9,324 . For the purpose of our study we chose the number that was derived from looking at actual response rates for the 2009 GSS survey data $(9,167)$, which was deemed reasonable as it falls approximately in the middle of the range of possible numbers we could use, and that would yield a conservative estimate of the number of women reporting abuse by an ex-partner or ex-spouse.

${ }^{15}$ Varcoe et. al. (2011). Op. cit. The study conducted by Varcoe et al. is predicated on 2006 census data which shows that there were 1,039,735 women who were separated or divorced and not living with a partner, and statistics derived from the 1993 Violence Against Women Survey, which showed that 50.7 percent of those surveyed reported physical assault from a former partner, 22.8 percent in the three years preceding the interview.

${ }^{16}$ Corso (2009). Op. cit.

${ }^{17}$ It is interesting to note that other jurisdictions that experience similar rates of domestic violence, such as Britain and Australia, approach the problem as a public health issue. The implications of this is that there is far more information available as governments tend to pay more attention to public health issues and there are established bodies to monitor incidence and prevalence so that the issue can be managed. 
Trying to determine an accurate count of the incidence and prevalence of domestic violence in Alberta has never been attempted, even though Alberta continues to be ranked as having either the highest, or second-highest rate of intimate partner violence in Canada. ${ }^{18}$ The textbox discusses the sources and various ways that an estimate of the prevalence can be obtained. However, the closest we can come to an accurate estimate of domestic violence in Alberta is to turn to the Family Violence in Canada report produced by the Canadian Centre for Justice Statistics.

The 2011 report Family Violence in Canada: A Statistical Profile reveals that of the 19 million Canadians that had a current or former spouse in 2009, six percent or 1.14 million reported that they had been either physically or sexually assaulted by their partner or spouse in the last five years. ${ }^{19}$ The percentage for Alberta overall, was 7.6 percent, with 6.5 percent of men, and 8.7 percent of women, reporting that they had either been physically or sexually assaulted in the past five years.

Closer analysis of the data presented in the Family Violence in Canada: A Statistical Profile, reveals that self-reported domestic violence is estimated at 17.4 percent for those who have an ex-spouse or partner, and only 3.8 percent for those with a current partner. ${ }^{20}$ Using these parameters, detailed analysis of the 2009 General Social Survey data for Alberta reveals that there were 45,837 women who indicated that they had an 'ex,' and that they had experienced one or more incidents of physical or sexual violence in the past five years, which is an average of 9,167 on an annual basis. This leads to an astonishing and very sobering conclusion that, every hour of every day, a woman in Alberta will undergo some form of interpersonal violence from an ex-partner or ex-spouse..$^{21}$

\section{The Cost of Ongoing Domestic Violence}

The 2011 study conducted by Varcoe et al, ${ }^{22}$ estimated the per-woman cost associated with having to deal with ongoing domestic violence, even after leaving an abusive relationship, to be approximately $\$ 13,162$ a year. ${ }^{23}$ These costs were deemed as being directly attributable to violence and were costs not realized by a comparison sample of women that had not experienced violence. ${ }^{24}$

${ }^{18}$ Canadian Centre for Justice Statistics. (2011). Family Violence in Canada: A Statistical Profile 2011. Statistics Canada, Canadian Centre for Justice Statistics. Catalogue no. 85-224-X Page 16. Table 1.1

${ }^{19}$ Ibid.

${ }^{20}$ Canadian Centre for Justice Statistics. (2011). Op. cit.

21 The calculation of this rate of incidence can be considered to be an underestimate and therefore a conservative number in that it excludes those who may currently be experiencing abuse from a current partner or spouse. The number of men who reported abuse by an 'ex' over the last five years in Alberta was calculated at 5,632 per year or 38 percent of the total population reporting some form of abuse from an 'ex' over the past five years

22 Op. cit.

23 The Varcoe study examined selected costs attributable to violence for a sample of 309 women who, on average, had been living separately from their partners for an average of 20 months and reported that they had experienced domestic violence after leaving the abusive situation. The findings were that the overall annual per woman cost attributable to violence in comparison to other samples of women was $\$ 13,162.39$. This includes total public sector costs of $\$ 11,369.77$ and total private costs of $\$ 1,792.62$.

${ }^{24}$ Varcoe et al. (2011). Op. cit. 
In order to estimate the cost of having to deal with ongoing domestic violence in Alberta, we can take the annual incidence rate calculated above, and using the per-woman cost associated with domestic violence that was identified in the Varcoe et al. study, we can conservatively estimate that having to address ongoing domestic violence, even after women have left an abusive situation, has cost more than $\$ 600$ million in the past five years, with $\$ 521$ million of this tab being picked up by Alberta taxpayers.

This estimate can be considered very conservative because it only includes a small range of costs that are directly attributable to violence, and focuses on the most basic health and nonhealth supports and services being utilized by women who have to deal with interpersonal violence after they have left an abusive situation. The costs included are those associated with accessing health services, such as emergency room visits, hospitalization, walk-in clinics, health testing, addictions counseling, etc., and a small range of non-health-related services such as legal aid, social assistance, employment insurance, counseling, etc. ${ }^{25}$

All of these costs are deemed as falling within the public sector and as such, are costing the government and the average taxpayer a great deal of money on an annual basis. It is important to stress that the calculation does not include other public sector costs associated with dealing with domestic violence such as police involvement, legal and court costs, lost time at work and the deleterious effects that witnessing domestic violence has on children. The \$521 million estimate therefore clearly underestimates the total cost burden that domestic violence has on Alberta taxpayers. Were these costs to be included in our study, our suspicion is that the ongoing cost of addressing domestic violence in Alberta would be well over \$1 billion in the last five years. ${ }^{26}$

\section{Prevention and Intervention are Cost Effective}

While understanding the range and full costs associated with domestic violence is important, it is just one piece of the puzzle. Knowing the cost does not necessarily tell us what we should do to prevent violence from happening in the first place. In today's world where there are finite resources to address a multitude of complex social problems, simply comparing the cost burdens associated with each social problem is not sufficient.

As Gold et al. point out in their analysis ${ }^{27}$ of the cost-effectiveness of health-care interventions to address domestic violence, the economic case for investing in domestic violence prevention initiatives requires more than an estimate of the total cost burden, because these estimates usually only reflect the costs of occurrences of domestic violence and the policy strategies that have been directed at resourcing the various social, policy and health-care systems downstream to meet the crisis needs of victims.

${ }^{25}$ The Varcoe study is considered conservative in that it only identifies and calculates costs for which they could obtain appropriate comparison groups, so as to accurately as possible delineate those costs that could be considered directly attributable to violence. It is also conservative as it does not include the full range of public-sector costs identified in other studies, and focuses only on women who have left, as opposed to women who are currently in a relationship marked by domestic violence.

${ }^{26}$ Based on other jurisdictions where comprehensive costing studies have been conducted, such as the United Kingdom and Australia, annual national costs range from a low of $\$ 5.8$ billion to a high of $\$ 13.9$ billion. See note 9 above.

${ }^{27}$ Gold, L., Norma, R., Devine, A., Feder G., Taft, A., \& Hegarty, K. (2011). “Cost effectiveness of health- care interventions to address intimate partner violence: What do we know and what else should we look for?" Violence against Women 17: 389-403. 
According to Gold et al., those who are seeking to truly influence a public policy response to domestic violence need to link the size of the economic impact to estimates of how the burden can be reduced through the implementation of cost-effective prevention interventions. In other words, if we re-orient policy discussions toward these upstream interventions to prevent firsttime victimization or perpetration, then it logically follows that society would benefit from the reduction in social and economic costs.

The potential returns to Canadian society are large. Evidence from cost-benefit studies of implemented prevention strategies for other social problems show that the return on investment for implementing these strategies range from a $\$ 2$ return for every dollar invested to as high as $\$ 20$ for every dollar invested. ${ }^{28,29}$

More concretely, following the Varcoe et al. cost estimate, ${ }^{30}$ each case of domestic violence that is prevented reduces the need for $\$ 11,370$ in spending on downstream interventions. The challenge is to identify cost-effective interventions for reducing or preventing domestic violence.

The review of literature containing cost-benefit information on interventions to address or prevent domestic violence in health or social sectors reveals that improved outcomes can be achieved at no statistically significant increase in costs, and that the value of improved health through violence prevention outweighs net intervention costs - whether that be through the implementation of programs, or as a result of implementing prevention policy. ${ }^{31}$ According to Gold et al., interventions that have been economically evaluated to date appear to be costeffective, offering improved outcomes at no statistically significant increase in costs, ${ }^{32}$ and that the value of improved health by preventing domestic violence more than outweighs net intervention costs. ${ }^{33}$

${ }^{28}$ Southwest Prevention Center, (2004). Cost benefit of Prevention: Review of the literature. Southwest Prevention Center, University of Oklahoma, Norman, Oklahoma.

${ }^{29}$ Research on the cost effectiveness of parenting programs show that the cost savings associated with the implementation of evidenced-based parenting programs yield cost-benefit ratios ranging from 1:3 to a high of 1:5. See, for example, Bonin, E., Stevens, M., Beecham, J., Byford, S. \& Parsonage, M. 2011. Costs and longer term savings of parenting programmes for the prevention of persistent conduct disorder: a modeling study. BMC Public Health 11: 803; Lee, S., Aos, S., \& Miller, M. (2008). Evidence-based programs to prevent children from entering and remaining in the child welfare system: Benefits and costs for Washington. Olympia: Washington State Institute for Public Policy, Document No. 08-07-3901; Mihalopoulos, C. 2004. Triple P Positive Parenting Program: Cost effectiveness analysis, School of Population Health, University of Melbourne, Australia.

30 Op. cit.

31 Gold et al. (2011). Op. cit.

32 Domino, M.E., Morrisey, J.P., Chung, S., Huntington, N., Larsen, M.J., \& Russell, L. A. (2005). "Service use and costs for women with co-occurring mental and substance use disorders and a history of violence," Psychiatric Services 56: 1223-1232.

33 Chanely, S., Chanely, J., \& Campbell, H. (2001). "Providing refuge: The value of domestic violence shelter services," American Review of Public Administration, 31: 393-413; Clark, K., Biddle, A., \& Martin, S. (2002). "A cost-benefit analysis of the Violence Against Women Act 1994," Violence Against Women 8: 417-428. 
Other areas of research that show promise in the reduction of domestic violence have to do with screening for domestic violence in health-care settings $;{ }^{34}$ the provision of intense advocacy-based psychological supports after disclosure of domestic violence, ${ }^{35}$ and home visitation and parenting programs as a strategy to reduce the incidence of domestic violence. ${ }^{36}$

\section{Promising Practices in the Prevention of Domestic Violence}

Recent research on health screening and advocacy programs (information, referral and support services) shows that they are able to reduce the incidence of domestic violence and subsequently enhance maternal health and wellbeing. ${ }^{37}$

For example, Australia's MOtherS' Advocates in the Community (MOSAIC) program used screening in a primary care setting to identify women at risk for experiencing violence during pregnancy. Those who met the criteria were then recruited to participate in a program that consisted of 12 months of weekly home visiting from trained and supervised local mothers offering non-professional befriending, advocacy, parenting support and referrals. ${ }^{38}$

The MOSAIC program was implemented in 106 primary care clinics in Melbourne, Australia, and the results of the study showed that the number of reported incidents of violence at followup was significantly lower than the comparison group. ${ }^{39}$ The study also found modest differences with the comparison group in depression scores, physical wellbeing scores, and mental wellbeing scores. And while there were no observed differences in parenting stress, 82 percent of the women mentored would recommend mentors to friends in similar situations. In addition to showing a reduction in incidents of violence for program participants, the program was also found to be cost-effective, with programming benefits outweighing costs by a ratio of $2: 1 .^{40}$

${ }^{34}$ Ramsay, J., Carter, Y., Davidson, L., Dunne, D., Eldridge, S., Feder, G., Hegarty, K., Rivas, C., Taft, A., \& Warburton, A. (2010). "Advocacy interventions to reduce or eliminate violence and promote the physical and psychological well-being of women who experience intimate partner abuse," International Journal of Women's Health 2: 183-197.

${ }^{35}$ Feder, G., Davies, R.A., Baird, K., Dunne, D., Eldridge, S., Griffiths, C., Gregory, A., Howell, A., Johnson, M., Ramsay, J., Rutherford, C., \& Sharp, D. (2011). "Identification and referral to improve safety (IRIS) of women experiencing domestic violence with a primary care training and support programme: A cluster randomized controlled trial," Lancet, 19;19;378 (9805):1788-95 Epub 2011 Oct 12.

36 Olds, D., Miller, T.R., Knudtson, M., Luckey, D., Bondy, J., Stevenson, A., Holmberg, J., Hanks, C., Kitzman, H., Anson, E., \& Arcoleo, K. (2011). Impact of the Nurse-Family Partnership on Neighborhood Context, Government Expenditures, and Children's School Functioning. National Criminal Justice Reference Service, Rockville, Maryland, U.S.A.

37 Ibid; Taft, A., Small, R., Hegarty, K., Watson, L., Gold, L., \& Watson, J. (2011). "MOtherS' Advocates in the Community (MOSAIC) - non-professional mentor support to reduce intimate partner violence and depression in mothers: A cluster randomized trial in primary care," BMC Public Health 11:178 accessed from www.biomedcentral.com, January 2012.

38 Ibid.

39 Results for the MOSAIC study showed that there was evidence of a true difference in mean abuse scores at follow-up in the intervention compared with the comparison arm (15.9 vs. 21.8, AdjDiff -8.67, CI -16.2 to -1.15). There was weak evidence for other outcomes, but a trend was evident favouring the intervention: proportions of women with CAS scores $\geq 7,51 / 88$ (58.4 percent) vs. $27 / 42$ (64.3 percent) AdjOR 0.47, CI 0.21 to 1.05); depression (EPDS score $\geq 13)(19 / 85,22$ percent (I) vs. 14/43, 33 percent (C); AdjOR 0.42, CI 0.17 to 1.06); physical wellbeing mean scores (PCS-SF36: AdjDiff 2.79; CI -0.40 to 5.99); mental wellbeing mean scores (MCS-SF36: AdjDiff 2.26; CI -1.48 to $6.00)$.

40 Taft et al. (2011). Op. cit. 
Similar effects have been found in the evaluation of the Nurse Family Partnership (NFP) program that has been operating across the United States for the past 30 years. The NFP is an evidence-based, community health program that helps transform the lives of vulnerable mothers pregnant with their first child. Each mother served by the program is partnered with a registered nurse early in her pregnancy and receives ongoing nurse home visits that continue through her child's second birthday.

Ongoing evaluation and research of the NFP over the last 30 years show that not only were incidents of domestic violence reduced, but other health and economic benefits were also realized such as reduced pregnancy complications, increased earnings, improved maternal and child mental health, improvements in children's education, and in one trial, an actual reduction in the number of domestic violence incidents by 37 percent for nurse-visited mothers, as compared to mothers who did not receive the program. ${ }^{4 l}$ Further research examining the impact of NFP on intimate partner violence is currently underway in British Columbia. ${ }^{42}$

Evaluation of the cost of implementing the Nurse Family Partnership indicates that nurse visitation costs range from US $\$ 2,914$ to US $\$ 6,463$ per family, with the average cost being US $\$ 4,500$ per family per year. ${ }^{43}$ Further research on the cost-benefits of the program revealed that cost savings and benefits derived from implementing Nurse Family Partnership yielded a cost-benefit ratio of $5.7: 1 .^{44}$ In other words, for every dollar spent, nearly $\$ 6$ of benefits in a wide range of health, education, child maltreatment, domestic violence and employment outcomes for women and children is realized by both the government and society at large.

\section{Potential Returns from Preventing Domestic Violence in Alberta}

The Family Violence in Canada: A Statistical Profile report indicates that Alberta has had one of the highest rates of self-reported domestic violence among Canadian provinces for the past 10 years. ${ }^{45}$ While there has been a decline from 9.9 percent in 1999 to 7.6 percent in 2009, Alberta's rate of self-reported domestic violence for men and women remains higher than the national average of 6.2 percent. In addition, at 8.7 percent, the percentage of women reporting domestic violence in Alberta is a full 2.3 percentage points higher than the national average of 6.4 percent. ${ }^{46}$ These rates alone demonstrate the need for the Alberta government to invest in the prevention of domestic violence.

\footnotetext{
${ }^{41}$ Olds et al. (2011). Op. cit.

42 Personal communication from Harriet MacMillan Professor, David R. Offord Chair in Child Studies Offord Centre for Child Studies McMaster University.

43 Nurse Family Partnership (2011). "Benefits and costs: A rigorously tested program with measurable results," retrieved January 2012 from: www.nursefamilypartnership.org.

${ }^{44}$ Karoly, L.A., Kilburn, R.M., \& Canon J. (2005) Early Childhood Interventions: Proven Results, Future Promise. Retrieved January 2012 from: www.rand.org.

${ }^{45}$ Canadian Centre for Justice Statistics. (2011). Op. cit.

${ }^{46}$ Canadian Centre for Justice Statistics. (2011). Op. cit. P. 16 Table 1.2.
} 
Research on the cost-effectiveness of prevention strategies shows that investing in evidencebased programming to prevent domestic violence can generate very tangible cost savings. For instance, the research conducted by Olds et al. ${ }^{47}$ has shown preliminary and encouraging results that the Nurse Family Partnership can reduce domestic violence rates by 37 percent. If this effect were to be realized in our current context, it would bring Alberta's self-reported victimization rate for women closer to the national average of 6.2 percent. If we limit our attention only to cases of domestic violence associated with partners who have left an abusive relationship, this could generate cost savings of over $\$ 44$ million per year. ${ }^{48}$

If the government of Alberta were to set a target of reducing domestic violence by 10 percent (approximately 1,500 cases per year), the cost for implementing the Nurse Family Partnership is estimated at approximately $\$ 9.6$ million per year. ${ }^{49}$ This annual cost, however, would be offset by the cost savings associated with the reduction in spending on services needed to deal with the effects of ongoing domestic violence (conservatively estimated to be over $\$ 19$ million annually in this scenario), and will generate net cost-benefits to both individuals and society of over $\$ 54$ million. $^{50}$

\section{CONCLUSION}

This paper has its origins in a larger project that set out to uncover the economic burden associated with domestic violence in Alberta. In examining the available evidence, it became clear that the detailed budgetary and service utilization information required for such an analysis was not readily available. What the exploratory work did uncover, however, was that there was evidence about the economic burden of domestic violence at a national level, albeit dated; that there was current information available on the economic burden associated with having to deal with ongoing domestic violence after women have left an abusive relationship; and that there was data on national and provincial incidence rates of domestic violence.

This evidence reveals that domestic violence after leaving a relationship is pervasive. In fact, every hour of every day, a woman in Alberta will undergo some form of domestic violence from an ex-partner or ex-spouse. And it is costly. The cost to Alberta taxpayers of addressing this ongoing domestic violence exceeds $\$ 1$ billion in the last five years.

\footnotetext{
47 Olds et al. (2011). Op. cit.

${ }^{48}$ If we consider only women who report ongoing abuse by an ex-spouse or partner, a 37 percent reduction in the numbers of Alberta women experiencing domestic violence would mean approximately 3,392 fewer women per year would be abused. If we apply Varcoe et al.'s per-woman estimate of $\$ 13,162$ in extra public and private costs, this would reduce a proportion of the social costs associated with domestic violence in Alberta by just over $\$ 44$ million per year. Of this, $\$ 38$ million would be a saving realized by government programs.

49 In calculating the implementation cost of MOSAIC and NFP, it was assumed that we could serve 500 families annually through the provision of NFP, and that another 1,000 women could be screened and referred to appropriate services on an annual basis. The maximum cost for NFP ( $\$ 6,463$ per family) was utilized, and the cost of $\$ 2,400$ per family was used to calculate the cost for implementing MOSAIC.

${ }^{50}$ The calculation of potential cost-benefits derived from the implementation of MOSAIC and NFP in Alberta assumes the realization of the benefits identified in the original NFP studies. Using the cost benefit ratio of 5.7:1, spending $\$ 5.6$ million would yield net cost-benefits of $\$ 31,920,000.00$.
} 
It also became clear that there is growing evidence for the cost effectiveness of prevention interventions that have the potential to affect the prevalence and incidence of domestic violence in the short term - such as the Nurse Family Partnership and MOSAIC. There is also evidence of the cost-effectiveness of strategies that could prevent first-time perpetration and victimization, such as Triple P Parenting, 4th $\mathrm{R}$ and Safe Dates. ${ }^{51}$

These latter strategies are directed upstream and are designed to influence the risk and protective factors that contribute to healthy relationships, and as such are deemed as having the potential to mitigate the occurrence of domestic violence. And while further research is required to determine whether programs such as 4 th $\mathrm{R}$ and Safe Dates are cost-effective in the long term, there is evidence that the cost-benefits associated with implementing Triple $\mathrm{P}$ Parenting are significant, get at the protective factors associated with the prevention of domestic violence and contribute to healthy developmental outcomes for children and families. ${ }^{52}$

To conclude, the purpose of this paper is quite modest: to identify existing evidence on the prevalence and cost of domestic violence, and to identify the existence of cost-effective public policies being practiced in other jurisdictions. The next step in this research agenda is to dig deeper into these possible public policy approaches to see which might work best in the Alberta context.

51 Programs such as Triple P Parenting, $4^{\text {th }} \mathrm{R}$, and Safe Dates, are evidence-based programs that support the development of the protective factors that contribute to healthy relationships and effective parenting, which are linked with the prevention of domestic violence.

52 Mihalopoulos, C. 2004. Triple P Positive Parenting Program: Cost effectiveness analysis, School of Population Health, University of Melbourne, Australia. 


\section{REFERENCES}

Begg, S., Vos, T., Barker, B., Stevenson, C., Stanley, L., \& Lopez, A. D. (2007). The Burden of Disease and Injury in Australia 2003. PHE 82. Australian Institute of Health and Welfare, Canberra.

Canadian Centre for Justice Statistics. (2011). Family Violence in Canada: A Statistical Profile 2011. Statistics Canada, Canadian Centre for Justice Statistics. Catalogue no. 85-224-X Page 16. Table 1.1

Chanely, S., Chanely, J., \& Campbell, H. (2001). "Providing refuge: The value of domestic violence shelter services. American Review of Public Administration," 31: 393-413.

Clark, K., Biddle, A., \& Martin, S. (2002). "A cost benefit analysis of the Violence Against Women Act 1994," Violence Against Women, 8: 417-428.

Corso, P. (2009). "Economic analysis and the prevention of intimate partner violence," in C. Mitchell \& D. Anglin (Eds.), Intimate partner violence: A health-based perspective, (pp. 53-60). Oxford University Press: New York.

Day, T., Mckenna, K., \& Bowlus, A. (2005). The Economic Costs of Violence Against Women: An Evaluation of the Literature. Expert brief compiled in preparation for the Secretary-General's in-depth study on all forms of violence against women. University of Western Ontario, London, Ontario, Canada.

Day, Tanis. (1995) “The Health Related Costs of Violence Against Women: The Tip of the Iceberg," first commissioned by the Canadian Advisory Council on the Status of Women, published by The Centre for Research on Violence Against Women and Children, University of Western Ontario, London, Ontario, Canada.

Department of Justice Canada. (2009). Family Violence: Department of Justice Canada Overview Paper 2009. Department of Justice Canada, Ottawa, Ontario, Canada. Online report available at http://www.justice.gc.ca/eng/pi/fv-vf/facts-info/fv-vf/fv-vf.pdf.

Domino , M.E., Morrisey, J.P., Chung, S., Huntington, N., Larsen, M.J., \& Russell, L. A. (2005). "Service use and costs for women with co-occurring mental and substance use disorders and a history of violence," Psychiatric Services 56: 1223-1232.

Feder, G., Davies, R.A., Baird, K., Dunne, D., Eldridge, S., Griffiths, C., Gregory, A., Howell, A., Johnson, M., Ramsay, J., Rutherford, C., \& Sharp, D. (2011). "Identification and referral to improve safety (IRIS) of women experiencing domestic violence with a primary care training and support programme: A cluster randomized controlled trial," Lancet, 19;19;378 (9805):1788-95 Epub 2011 Oct 12.

Feder, G., Ramsay, J., Dunne, D., Rose M., Arsene, C., Norman, R., Kuntze, S., Spencer, A., Bacchus, L., Hague, G., Warburton, A., \& Taket, A. (2009). "How far does screening women for domestic (partner) violence in different health care settings meet criteria for a screening programmme? Systematic reviews on nine U.K," National Screening Committee criteria. Cochrane data base Review 2009.

Godenzi, A. \& Yodanis, C. (2000). "The benefits of studying costs: A review and agenda for studies on the economic costs of violence against women," Policy Studies, 21(3): 263-276.

Gold, L., Norma, R., Devine, A., Feder G., Taft, A., \& Hegarty, K. (2011). "Cost- effectiveness of health care interventions to address intimate partner violence: What do we know and what else should we look for?" Violence against Women, 17: 389-403.

Greaves, L., Hankivsky, O., \& Kingston-Riechers, J. (1995). Selected Estimates of Costs of Violence against Women. Centre for Research on Violence against Women and Children, London, Ontario, Canada.

Karoly, L.A., Kilburn, R.M., \& Canon J. (2005) Early Childhood Interventions: Proven Results, Future Promise. Retrieved January 2012 from: www.rand.org. 
Mihalopoulos, C. 2004. Triple P Positive Parenting Program: Cost effectiveness analysis, School of Population Health, University of Melbourne, Australia.

Norman, R., Spencer, A., Eldridge, S. \& Feder, G. (2010) "Cost-effectiveness of a programme to detect and provide better care for female victims of intimate partner violence," Journal of Health Services Research and Policy, 15: 143-149.

Nurse Family Partnership (2011). "Benefits and costs: A rigorously tested program with measurable results," retrieved January 2012 from: www.nursefamilypartnership.org.

Olds, D., Miller, T.R., Knudtson, M., Luckey, D., Bondy, J., Stevenson, A., Holmberg, J., Hanks, C., Kitzman, H., Anson, E., \& Arcoleo, K. (2011). Impact of the Nurse-Family Partnership on Neighborhood Context, Government Expenditures, and Children's School Functioning. National Criminal Justice Reference Service, Rockville, Maryland, U.S.A.

Prevention Action (2011). "Speaking the language of policy," Prevention Action, October 2011.

Retrieved October 31, 2011 from http://www.preventionaction.org.

Ramsay, J., Carter, Y., Davidson, L., Dunne, D., Eldridge, S., Feder, G., Hegarty, K., Rivas, C., Taft, A., $\&$ Warburton, A. (2010). "Advocacy interventions to reduce or eliminate violence and promote the physical and psychological well-being of women who experience intimate partner abuse," International Journal of Women's Health 2: 183-197.

Southwest Prevention Center, (2004). Cost benefit of Prevention: Review of the literature. Southwest Prevention Center, University of Oklahoma, Norman, Oklahoma.

Taft, A., Small, R., Hegarty, K., Watson, L., Gold, L., \& Watson, J. (2011). “MOtherS' Advocates in the Community (MOSAIC) - non-professional mentor support to reduce intimate partner violence and depression in mothers: A cluster randomized trial in primary care," BMC Public Health 11:178 accessed from www.biomedcentral.com, January 2012.

Varcoe, O., Hankivsky, M., Ford-Gilboe, J., Wuest, P., Wilk, J., Hammerton, J., and Campbell, J. (2011). "Attributing selected costs to intimate partner violence in a sample of women who have left abusive partners: A social determinants of health approach," Canadian Public Policy - Analyse de politiques, 37(3): $1-21$.

Walby, S. (2004). The Cost of Domestic Violence. Women and Equality Unit, London, U.K.

Walby, S. (2009). The Cost of Domestic Violence: Update 2009. Lancaster University, Lancaster, U.K. 


\section{ABOUT THIS PUBLICATION}

The School of Public Policy Research Papers provide in-depth, evidence-based assessments and recommendations on a range of public policy issues. Research Papers are put through a stringent peer review process prior to being made available to academics, policy makers, the media and the public at large. Views expressed in The School of Public Policy Research Papers are the opinions of the author(s) and do not necessarily represent the view of The School of Public Policy.

\section{OUR MANDATE}

The University of Calgary is home to scholars in 16 faculties (offering more than 80 academic programs) and 36 Research Institutes and Centres including The School of Public Policy. Under the direction of Jack Mintz, Palmer Chair in Public Policy, and supported by more than 100 academics and researchers, the work of The School of Public Policy and its students contributes to a more meaningful and informed public debate on fiscal, social, energy, environmental and international issues to improve Canada's and Alberta's economic and social performance.

The School of Public Policy achieves its objectives through fostering ongoing partnerships with federal, provincial, state and municipal governments, industry associations, NGOs, and leading academic institutions internationally. Foreign Investment Advisory Committee of the World Bank, International Monetary Fund, Finance Canada, Department of Foreign Affairs and International Trade Canada, and Government of Alberta, are just some of the partners already engaged with the School's activities.

For those in government, The School of Public Policy helps to build capacity and assists in the training of public servants through degree and non-degree programs that are critical for an effective public service in Canada. For those outside of the public sector, its programs enhance the effectiveness of public policy, providing a better understanding of the objectives and limitations faced by governments in the application of legislation.

\section{DISTRIBUTION}

Our publications are available online at www.policyschool.ca.

\section{DISCLAIMER}

The opinions expressed in these publications are the authors alone and therefore do not necessarily reflect the opinions of the supporters, staff, or boards of The School of Public Policy.

\section{COPYRIGHT}

Copyright (C) 2012 by The School of Public Policy.

All rights reserved. No part of this publication may be reproduced in any manner whatsoever without written permission except in the case of brief passages quoted in critical articles and reviews.

\section{ISSN}

1919-112x SPP Research Papers (Print)

1919-1138 SPP Research Papers (Online)

\section{DATE OF ISSUE}

June 2012

\section{MEDIA INQUIRIES AND INFORMATION}

For media inquiries, please contact Morten Paulsen at 403-453-0062.

Our web site, www.policyschool.ca, contains more information about The School's events, publications, and staff.

\section{DEVELOPMENT}

For information about contributing to The School of Public Policy, please contact Courtney Murphy by telephone at 403-210-7201 or by e-mail at cmurphy@ucalgary.ca.

\section{EDITOR}

Timothy Giannuzzi 


\section{RECENT PUBLICATIONS BY THE SCHOOL OF PUBLIC POLICY}

\section{NEGOTIATED SETTLEMENTS: LONG-TERM PROFITS AND COSTS}

http:/ / policyschool.ucalgary.ca/ ?q=content/ negotiated-settlements-long-term-profits-and-costs.pdf

G Kent Fellows | May 2012

REFORMING THE TAX MIX IN CANADA

http:/ / policyschool.ucalgary.ca/?q=content/reforming-tax-mix-canada.pdf

Bev Dahlby | April 2012

TAXING CONSUMPTION OR INCOME: DU PAREIL AU MÊME?

http:// policyschool.ucalgary.ca/sites/ default/files/research/cnossen-taxing-consumption.pdf Sijbren Cnossen | April 2012

THE GST/HST: CREATING AN INTEGRATED SALES TAX IN A FEDERAL COUNTRY http:// policyschool.ucalgary.ca/ sites/default/files/research/bird-gst-hst.pdf Richard M. Bird | April 2012

A PROPOSAL TO CREATE A PAN-CANADIAN ENERGY INFORMATION ORGANIZATION (CEIO) http:/ / policyschool.ucalgary.ca/ sites/default/files/research/m-moore-pancanadian.pdf Michal C. Moore | April 2012

ASSISTED REPRODUCTION POLICY IN FEDERAL STATES: WHAT CANADA SHOULD LEARN FROM AUSTRALIA http:/ / policyschool.ucalgary.ca/ sites/ default/files/ research/ dave-snow-art-final.pdf Dave Snow and Rainer Knopff | April 2012

THE ROLE OF CROWN CORPORATIONS IN THE CANADIAN ECONOMY - AN ANALYTICAL FRAMEWORK http:/ / policyschool.ucalgary.ca/ sites/default/files/research/ privatization-crown-corp.pdf Edward M. Iacobucci and Michael J. Trebilcock | March 2012

TANTALUS UNBOUND: GOVERNMENT POLICY AND INNOVATION IN CANADA http:// policyschool.ucalgary.ca/sites/default/files/research/macintosh-final.pdf Jeffrey G. MacIntosh | March 2012

IMPLICATIONS OF THE RECOMMENDATIONS OF THE EXPERT PANEL ON FEDERAL SUPPORT TO RESEARCH AND DEVELOPMENT

http:// policyschool.ucalgary.ca/sites/default/files/research/mintzmanning-fed-supp-1.pdf Preston Manning and Jack Mintz | March 2012

SMART ENVIRONMENTAL POLICY WITH FULL-COST PRICING http:// policyschool.ucalgary.ca/sites/default/files/research/olewiler-online.pdf Nancy Olewiler | March 2012

DEPARTURES FROM NEUTRALITY IN CANADA'S GOODS AND SERVICES TAX http:/ / policyschool.ucalgary.ca/sites/default/files/research/m-smart-gst-012.pdf Michael Smart | February 2012

SOME OBSERVATIONS ON THE CONCEPT AND MEASUREMENT OF INCOME INEQUALITY http:// policyschool.ucalgary.ca/sites/default/files/research/richardson-comm2.pdf Stephen R. Richardson | February 2012

A REVIEW AND ASSESSMENT OF PRIVATIZATON IN CANADA http:// policyschool.ucalgary.ca/sites/ default/files/research/boardman-vining-privatization.pdf Anthony E. Boardman and Aidan R. Vining | January 2012 